\title{
Classification and evaluation of tight sandstone reservoirs based on diagenetic facies: a case study on Chang 6 reservoir in the center-west Ordos Basin
}

\author{
Gao Zhanwu $^{1,2} \cdot$ Shi Jian ${ }^{1,3} \cdot$ Xie Qichao $^{1,3} \cdot$ Zhou Yan $^{4} \cdot$ Zhou Shuxun $^{1,3}$
}

Received: 2 August 2021 / Accepted: 7 November 2021 / Published online: 22 November 2021

(c) The Author(s) 2021

\begin{abstract}
Tight sandstone reservoirs dominated by are developed in the Chang 6 oil layer group of the Yanchang Formation in the central-western part of the Ordos Basin. Featuring the lacustrine delta facies, Chang 6 formation in the center-west area of Ordos Basin shows an increasing petroleum reserve expectation. Its exploitation practice, however, has many problems caused by tight sandstone reservoir features. According to diagenetic and pore analysis, the diagenetic facies in the study area are grouped into four types: chlorite-film-intergranular-pore, feldspar-dissolution, clay-cemented-micropore, carbonatecemented-tightness for their obvious differences in mineral feature and pore evolution. By introducing the comprehensive classification parameter synthesized from 9 other parameters, the reservoir quality is divided up into four levels: $\mathrm{I}\left(\mathrm{F}_{\mathrm{eci}}>1\right)$, $\mathrm{II}\left(3 \leq \mathrm{F}_{\mathrm{eci}} \leq 7\right)$, III $\left(-2 \leq \mathrm{F}_{\mathrm{eci}} \leq 3\right), \mathrm{IV}\left(\mathrm{F}_{\mathrm{eci}} \leq-2\right)$. The reservoir quality division matches well with the diagenetic facies group. To decide the diagenetic type and reservoir quality division in all wells, the logging data are utilized with the Fisher discriminant method, which has obtained a good performance. The method enables the reservoir quality analysis expanding to all wells from samples, which is helpful for exploitation of the study area.
\end{abstract}

Keywords Diagenetic facies $\cdot$ Logging quantitative characterization - Comprehensive evaluation of reservoirs · Tight sandstone $\cdot$ Ordos Basin

\section{Introduction}

\section{Research idea}

Diagenetic facies, one of major factors that shape reservoir quality and pore-throat structure, is a reservoir genetic unit featuring petrophysical and seepage properties (Zou et al. 2008). Its core content involves reservoir evolution

Shi Jian

shijian2371@163.com

1 National Engineering Laboratory for Exploration and Development of Low-Permeability Oil \& Gas Fields, Xi' an Shaanxi 710018, China

2 PetroChina Changqing Oilfield Company, Xi'an 710018, Shaanxi, China

3 Exploration and Development, Research Institute of PetroChina Changqing Oilfield Company, Xi' an 710018, Shaanxi, China

4 CNPC Logging Applied Research Institute, Xi' an 710077, China mechanisms which dominate how and where petroleum enriches, particularly when basic accumulation conditions are confirmed. Thus, diagenetic facies-oriented research is helpful to make an accurate evaluation and prediction on tight sandstone reservoir (Fu et al. 2013; Frebch et al. 2012; Taylor et al. 2010; Lai et al. 2015; Maas et al. 2011; Morad et al. 2010). As one of major development formations in the center-west area of Ordos Basin, Chang 6 sees a growing proved reserve for years with a favorable expectation. Due to heavy tightness from strong diagenesis, Chang 6 formation has many complex and unsolved problem involving pore structure and evolution. Thus firstly, this paper reveals diagenesis and pore feature and then classifies diagenetic facies. Secondly, the relationship between diagenetic facies and reservoir quality is built up. Lastly, applying logging data into discerning diagenetic facies is executed at all wells. This work is full of meaning for it not only makes diagenetic facies classification at every well feasible but provides the prediction of petroleum enrichment with novel data. 


\section{Geological background}

The Ordos Basin is very rich in tight oil and gas resources and has broad prospects for exploration and development (Yang et al. 2013; Guo et al. 2017). It is the second largest sedimentary basin in China. It is structurally located on the western edge of the North China Craton (Yang et al. 2005; Li et al. 2010). The internal structure of the basin is relatively simple, and the strata is relatively gentle. The overall performance is characterized by a wide east wing and a steep and narrow west wing. It is a large monoclinic with a gentle west dip (Fig. 1). The structure of the midwestern region is located inside the Yishan slope, adjacent to the Tianhuan oil-generating sag (Fig. 1). The Yanchang Formation develops a set of inland depression-type open lake delta deposits (Fu et al. 2005; Wang et al. 2006; Li et al. 2006; Deng et al. 2008). According to lithology and sedimentary cycle, it can be divided into 10 oil layer groups from top to bottom (Fig. 1): Since the Chang 10th period, the lake basin shape of the early Yanchang Formation has gradually formed. In the Chang 9-Chang 8 period, the sinking rate of the lake basin accelerated due to the violent faulting activities in the edge of the basin, and the lake shoreline continued to advance and expand from the inside to the outside. By the Chang 7 sedimentary period, the evolution of the lake basin reached its heyday, with the largest lake area and the deepest water depth reaching $60 \mathrm{~m}$. The lake basin gradually shrank during the 6 th to 2nd stage. Then, the lake basin depression of Chang 1 oil layer group disappeared ( $\mathrm{Li}$ et al. 2012; Liao et al. 2012).

The Chang 6 reservoir in the midwestern part of the Ordos Basin is mainly composed of dark gray fine-grained feldspar sandstone and lithic feldspar sandstone, showing the characteristics of low quartz and high feldspar, and a moderate degree of structural maturity (Fig. 2). The main

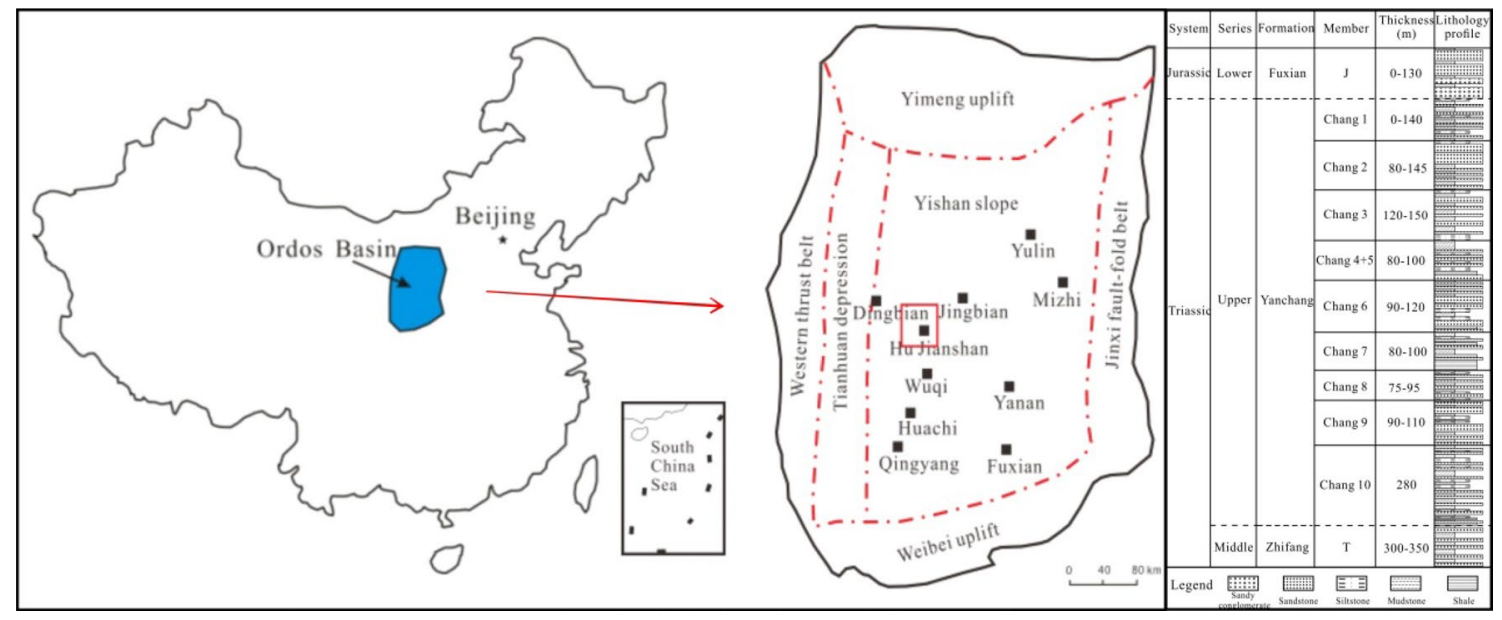

Fig. 1 Geographical location of the midwestern regions, Ordos Basin
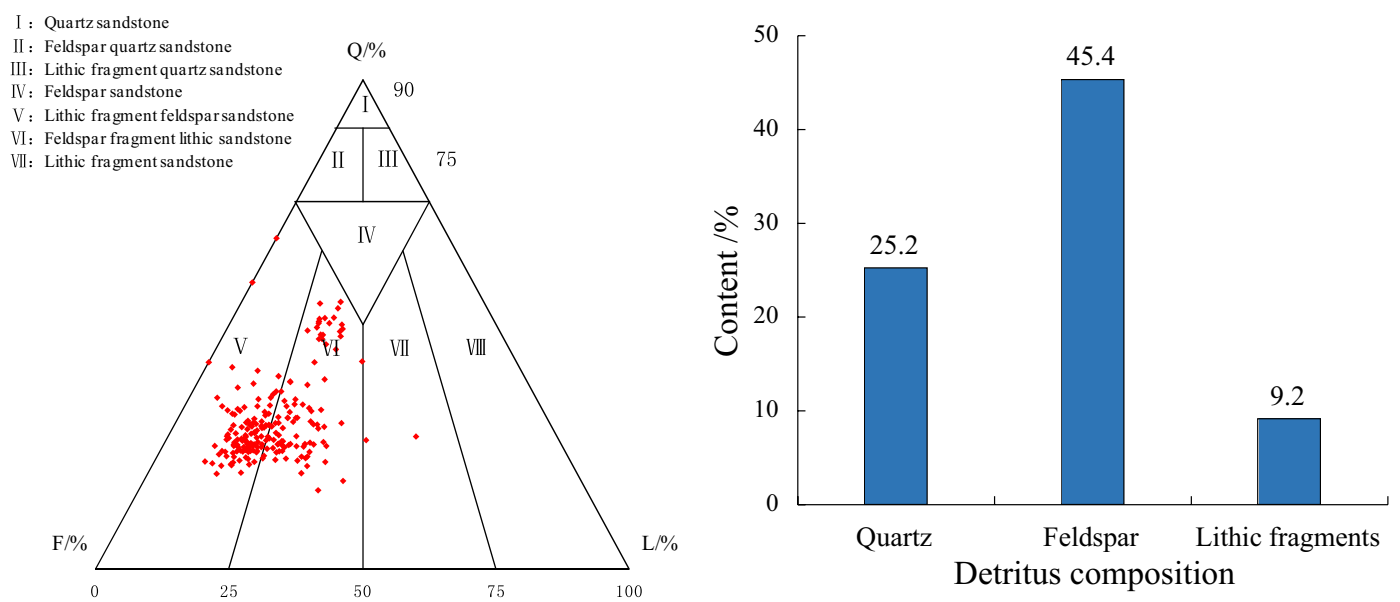

Fig. 2 Sandstone triangle diagram (left) and histogram of clastic composition distribution (right) 
distribution range of the peak porosity is between 7.5 and $15 \%$, with an average of $10.67 \%$; the main distribution range of the peak permeability is within $<0.3 \times 10^{-3} \mu \mathrm{m}^{2}$, with an average of $0.53 \times 10^{-3} \mu \mathrm{m}^{2}$ (Fig. 3). The average content of interstitial materials is about $13.4 \%$, mainly authigenic clay minerals such as chlorite (3.8\%), kaolinite (2.5\%), illite $(1.7 \%)$ and iron calcite (2.8\%), followed by silica (1.2\%) (Table 1, Fig. 4); the pore types are mainly intergranular pores (3.25\%) and feldspar dissolved pores (0.78\%) (Fig. 4).

The Chang 6 reservoir in the midwestern part of the Ordos Basin is mainly composed of dark gray fine-grained feldspar sandstone and lithic feldspar sandstone, showing the characteristics of low quartz and high feldspar, and a moderate degree of structural maturity (Fig. 2). The main distribution range of the peak porosity is between $7.5 \%$ and $15 \%$, with an average of $10.67 \%$; the main distribution range of the peak permeability is within $<0.3 \times 10^{-3} \mu \mathrm{m}^{2}$, with an average of $0.53 \times 10^{-3} \mu \mathrm{m}^{2}$ (Fig. 3). The average content of interstitial materials is about $13.4 \%$, mainly authigenic clay minerals such as chlorite $(3.8 \%)$, kaolinite $(2.5 \%)$, illite $(1.7 \%)$ and iron calcite $(2.8 \%)$, followed by silica $(1.2 \%)$ (Table 1, Fig. 4); the pore types are mainly intergranular pores (3.25\%) and feldspar dissolved pores (0.78\%) (Fig. 4).

\section{Diagenetic facies types and geological characteristics}

\section{Classification of diagenetic facies}

Scholars all over the world have not yet reached a consensus on the naming and classification of diagenetic facies to form a unified classification standard. The main reference factors can be attributed to various aspects such as diagenetic minerals, diagenesis, rock structure composition, porosity and permeability, reservoir characteristics, diagenetic environment, geophysical characteristics and practical perspectives of exploration. Chinese scholars often name and classify diagenetic facies based on the differences in diagenetic evolution characteristics such as diagenesis and degree, mineral type and content (Zou et al. 2005, 2007; Zhang et al. 2011; Shi et al. 2011). The division of diagenetic facies is based on previous principles and combined with diagenetic phenomena in the main study area. Based on the observation of 258 sections in 36 wells in this area and the analysis and statistics of identification data, differences in mineral characteristics, pore types and distribution characteristics are analyzed. Finally, the study area was divided into four diagenetic facies types: residual chlorite-membrane intergranular-pore diagenetic facies, feldspar dissolution diagenetic facies, clay mineral cemented microporous diagenetic facies, carbonate cemented tight diagenetic facies (Table 2).

\section{Differences in reservoir characteristics of different diagenetic facies}

(1) Residual chlorite-membrane intergranular-pore diagenetic facies.

The main diagenesis feature is the development of chlorite membranes on the edges of detrital quartz particles (Fig. 5a), and the intergranular pores are relatively well preserved. Early chlorite adheres to the surface of clastic particles in the form of thin film. The appearance of chlorite film inhibits the increase in quartz in the later period
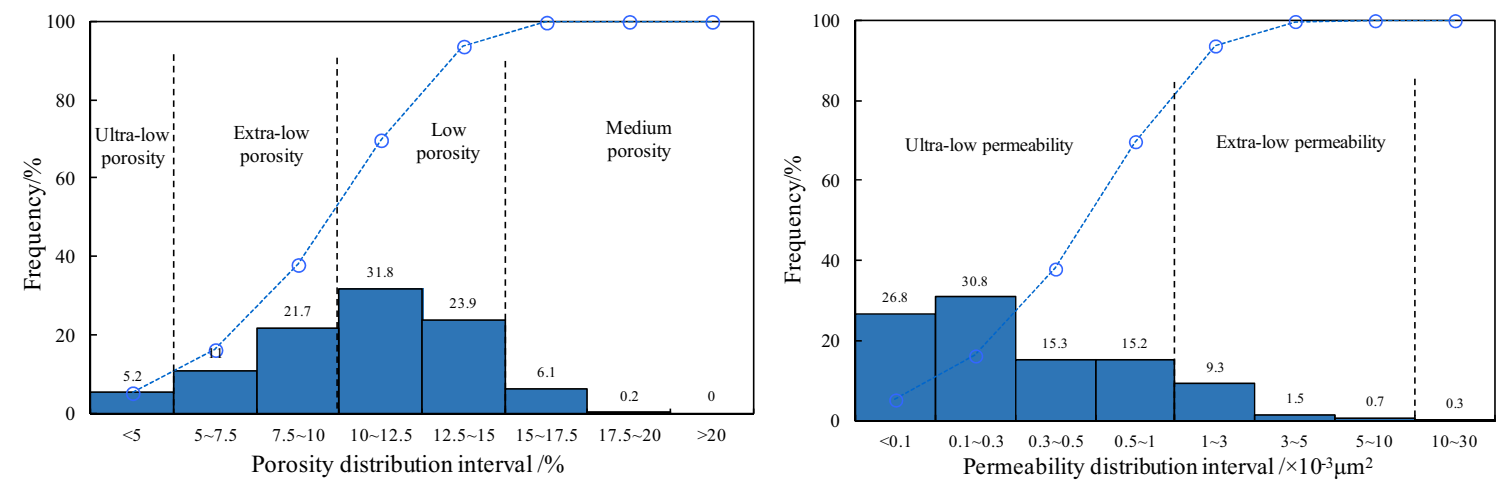

Fig. 3 Histogram of reservoir physical property distribution

Table 1 Reservoir interstitial content statistics table

\begin{tabular}{lllllllllll}
\hline Level & Chlorite\% & Illite $\%$ & Kaolinite $\%$ & Reticulated clay\% & Calcite\% & Ferrocalcite $\%$ & Silicic\% & Feldspar \% & others\% & Total\% \\
\hline Chang 6 & 3.8 & 1.7 & 2.5 & 0.3 & 0.3 & 2.8 & 1.2 & 0.2 & 0.6 & 13.4 \\
\hline
\end{tabular}




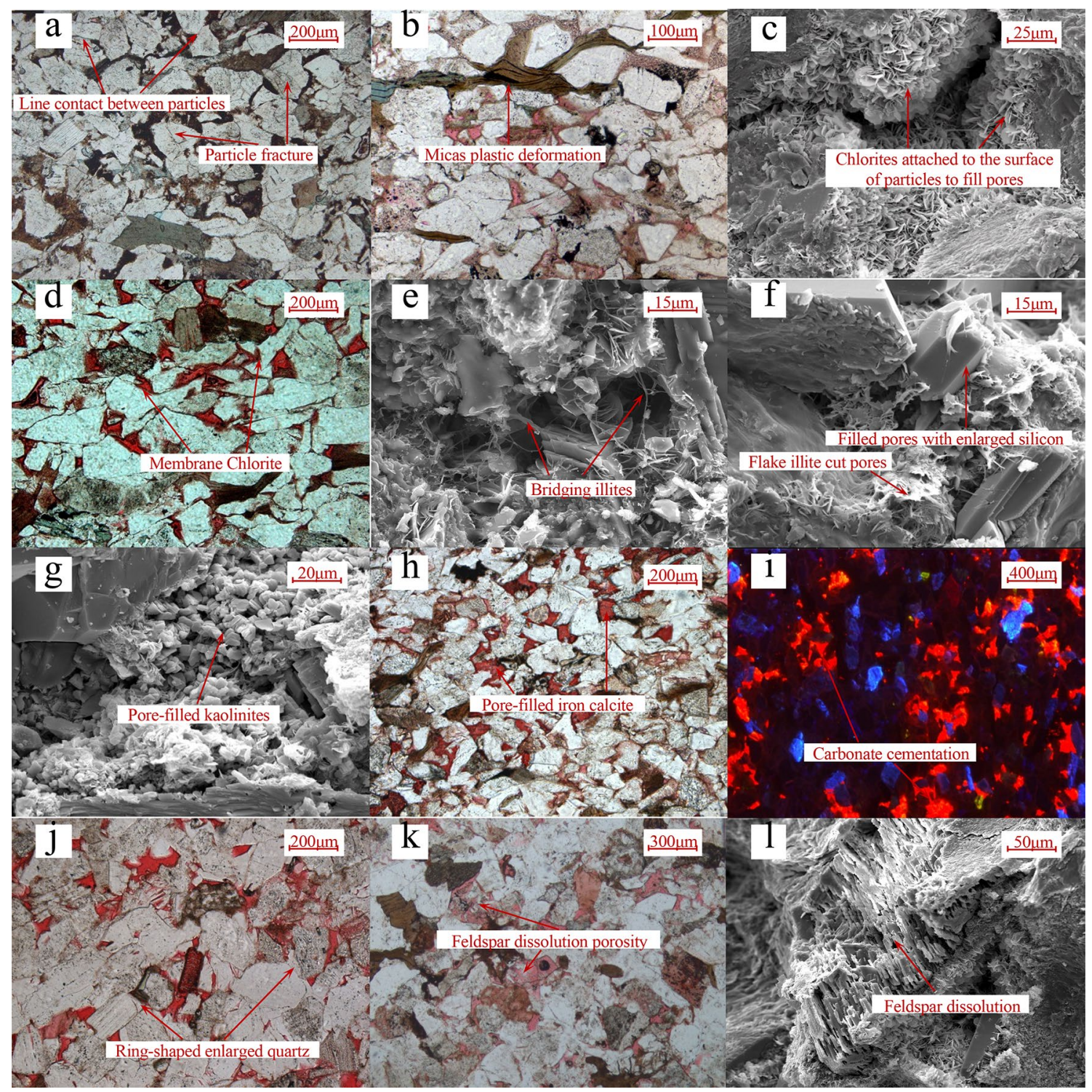

Fig. 4 Microscope figures of typical diagenetic phenomena of samples

Table 2 Statistical table of diagenetic features

\begin{tabular}{|c|c|c|c|c|c|c|}
\hline Diagenetic facies type & Porosity/\% & $\begin{array}{l}\text { Permeabil- } \\
\text { ity } / \times 10^{-3} \mu \mathrm{m}^{2}\end{array}$ & $\begin{array}{l}\text { Surface } \\
\text { poros- } \\
\text { ity } / \%\end{array}$ & $\begin{array}{l}\text { Rock } \\
\text { density/(g/ } \\
\left.\mathrm{cm}^{3}\right)\end{array}$ & $\begin{array}{l}\text { Interstitial } \\
\text { content } / \%\end{array}$ & Pore combination \\
\hline $\begin{array}{l}\text { Residual chlorite-membrane intergranular- } \\
\text { pore diagenetic facies }\end{array}$ & 12.51 & 0.73 & 5.16 & 2.46 & 14.7 & Dissolution pore-intergranular pore \\
\hline Feldspar dissolution diagenetic facies & 10.03 & 0.58 & 4.87 & 2.51 & 12.58 & Intergranular pore-dissolved pore \\
\hline $\begin{array}{l}\text { Clay mineral cemented microporous } \\
\text { diagenetic facies }\end{array}$ & 7.99 & 0.35 & 2.27 & 2.55 & 15.25 & Dissolved pores-micropores \\
\hline Carbonate cemented tight diagenetic facies & 5.37 & 0.18 & 2.35 & 2.57 & 14.95 & Micropores \\
\hline
\end{tabular}

and retains some primary pores. The protection of reservoir is stronger than that of filling pores. They are the main pore type, locally connected with dissolved pores to form dissolution-enlarged intergranular pores. The attachment of the chlorite film to the particles shows that it not only plays a certain anti-compaction effect, but also protects the

\footnotetext{
1

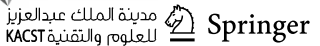




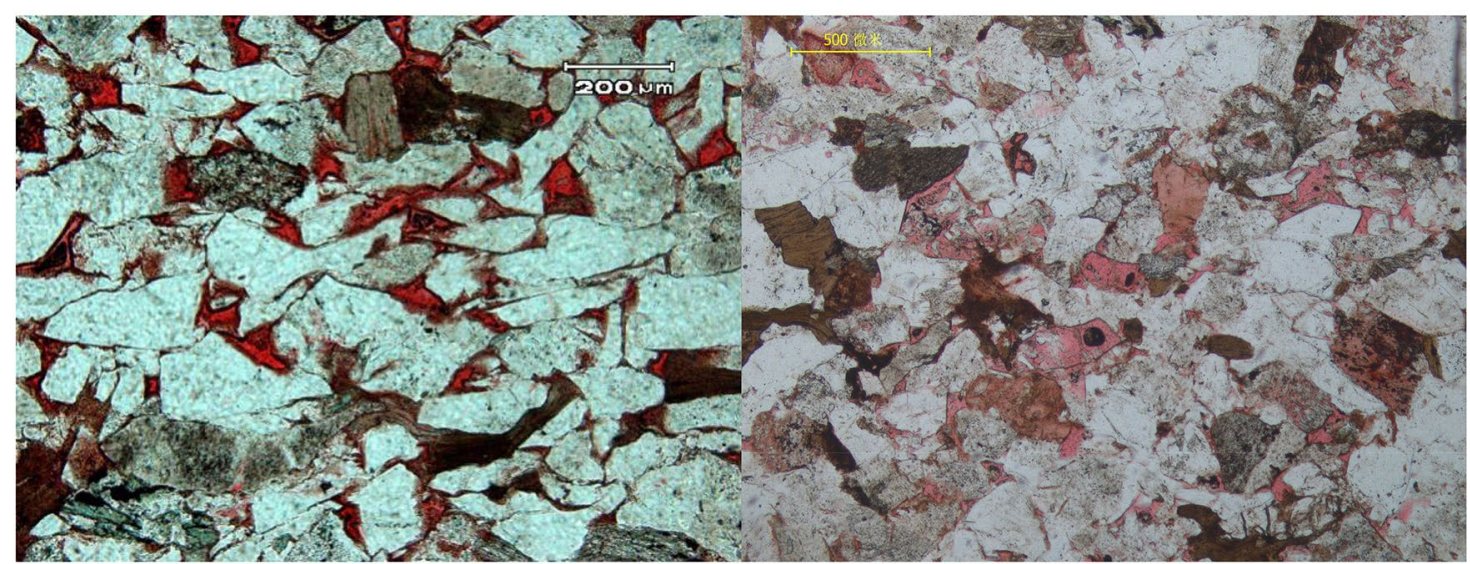

a. Chlorite film developed, Well A49, 1901.6m

b. Feldspar dissolution, Well A228, 1949.1 m

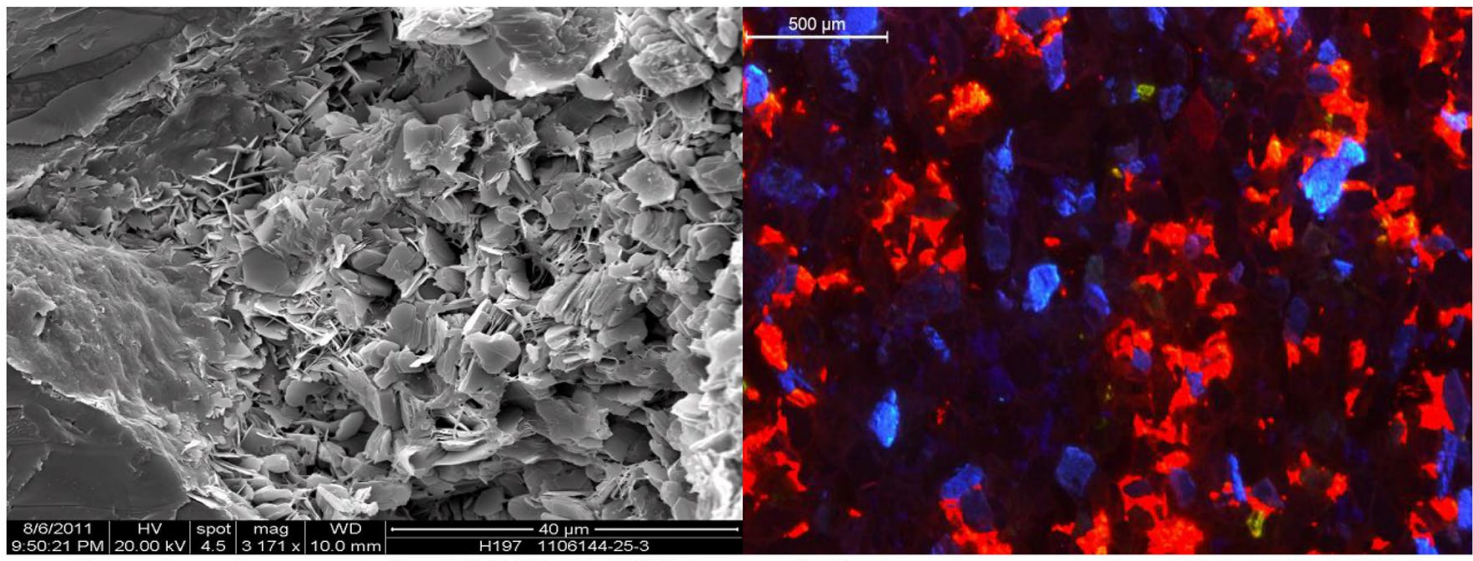

c. Clay minerals cementation Well H197, 1909.4m

d. Carbonate cementation, Well A265, 1996.6m

Fig. 5 Microscopic features of different diagenetic facies zones

particles, including wrapping the particles to avoid reaction with pore fluid and inhibiting the secondary growth of silica. The average rock density in this diagenetic facies zone is $2.46 \mathrm{~g} / \mathrm{cm}^{3}$, the average interstitial volume content is $14.7 \%$, the pore combination is dominated by dissolved pores-intergranular pores, and the high pressure mercury injection has low threshold pressure and tends to be coarser. It shows that the pore throat sorting performance is better, the median radius is larger, the main peak value of pore throat mercury ingress and permeability contribution value are both at $>1 \mu \mathrm{m}$, and the connectivity is good. The physical properties of the reservoir are relatively good, with an average porosity of $12.51 \%$ and an average permeability of $0.73 \times 10^{-3} \mu \mathrm{m}^{2}$, respectively, which are the most favorable diagenetic facies belt in the study area (Table 2, Fig. 6a).

(2) Feldspar dissolution diagenetic facies.

The main diagenetic feature is that the content of intergranular pores has decreased, and the pore types are mostly dissolved pores formed by partial or full dissolution of feldspar particles or soluble lithic debris (Fig. 5b). Compared with compaction and cementation, secondary pores generated by dissolution are relatively limited, but they are still of great significance to the improvement of reservoir physical properties. The average density of rocks in the diagenetic facies belt is $2.51 \mathrm{~g} / \mathrm{cm}^{3}$, and the volume content of interstitials is $12.58 \%$. The pore combination is dominated by intergranular pores-dissolved pores, and the high-pressure mercury intrusion threshold pressure is lower, which tends to be coarser. It shows that the pore throat sorting performance is better, the median radius is larger, the main peak value of the pore throat mercury inflow and the permeability contribution value are between 0.5 and $1 \mu \mathrm{m}$, and the connectivity is good. The physical properties of the reservoir are slightly worse than the remaining intergranular pores of the chlorite membrane. The average porosity is $10.03 \%$, and the average permeability is $0.58 \times 10^{-3} \mu \mathrm{m}^{2}$, respectively. It is a more favorable diagenetic facies belt in the study area (Table 2, Fig. 6a).

(3) Clay mineral cemented microporous diagenetic facies.

The main diagenetic feature is that the primary intergranular pores are filled by authigenic clay minerals such as chlorite, illite and kaolinite, and the intercrystalline pores of the

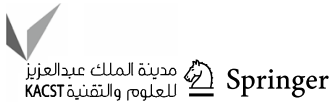




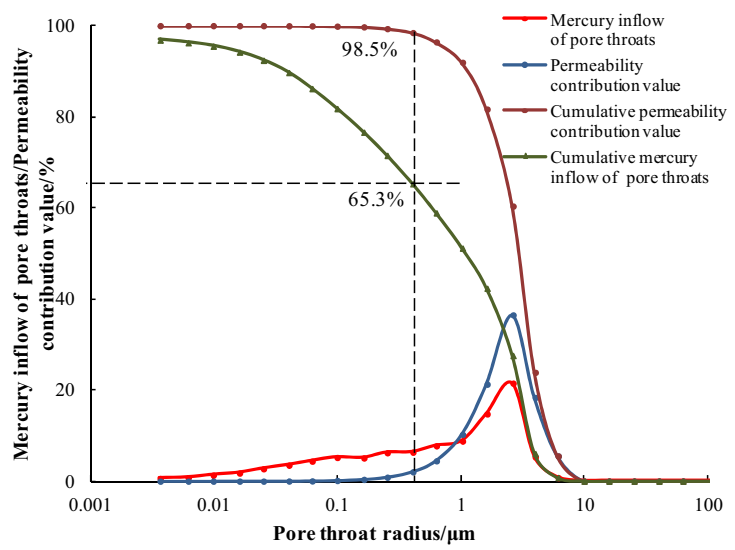

a. Residual chlorite-membrane intergranular-pore diagenetic facies, A3, 1945.2m

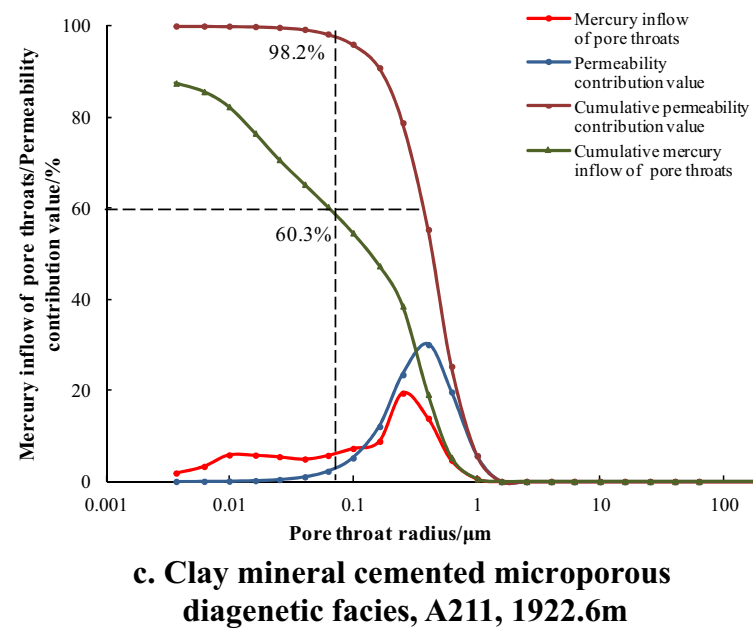

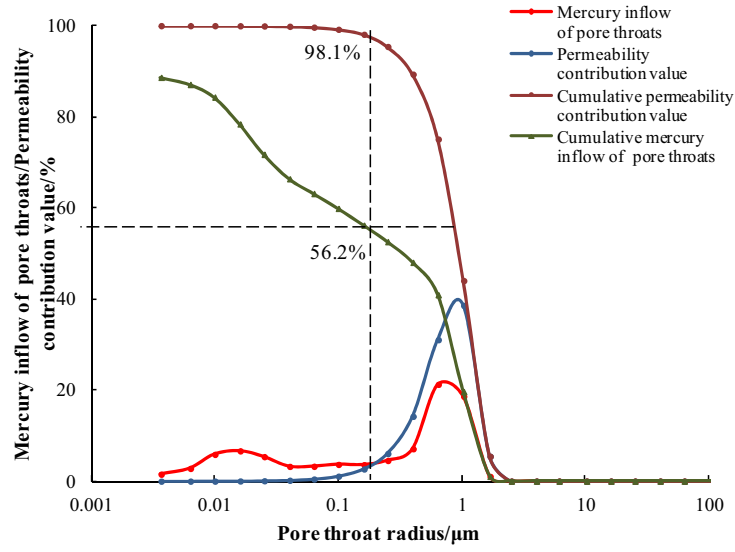

b. Feldspar dissolution diagenetic facies, Y182, 2101.2m

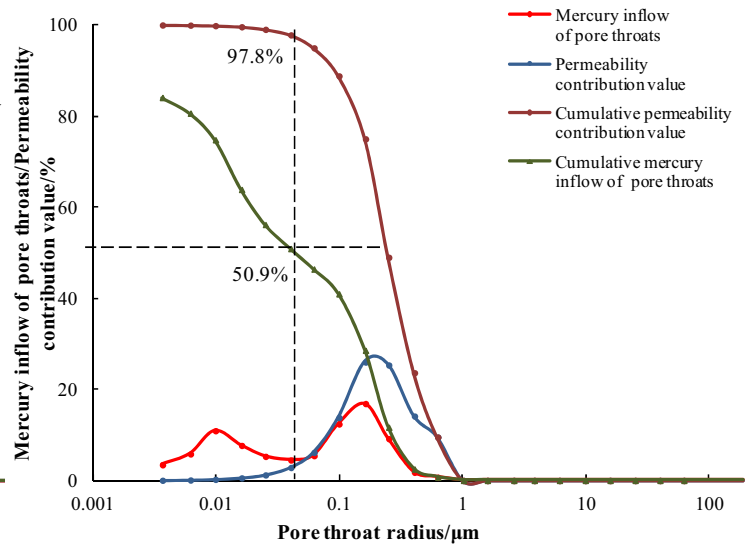

d. Carbonate cemented tight diagenetic facies, Y144, 2178.4m

Fig. 6 Different types of pressure curves and pore throat distribution characteristics

clay minerals are developed (Fig. 5c). The damage degree of bridged illite or filled illite to throat is stronger than that of pores, which also improves the compaction resistance of reservoir to a certain extent. Kaolinite has a certain destructive effect on porosity, but the generation of kaolinite not only has certain intergranular pores, but also is often accompanied by the dissolution of feldspar to produce dissolution pores, which can improve the reservoir to a certain extent and will not cause a wide range of physical properties reduction. The average rock density in this diagenetic facies belt is $2.55 \mathrm{~g} / \mathrm{cm}^{3}$, and the average interstitial volume content is $15.25 \%$. The pore combination is dominated by dissolved pores and micropores. The high-pressure mercury intrusion threshold pressure is generally higher, and the skewness tends to be fine, reflecting the greater degree of pore throat heterogeneity. The median radius is generally small, the pore throats are severely damaged by the cementation in the later stage, and the pore throat configuration relationship is poor, the number of mesopore throats is reduced, and the cumulative mercury intake from the pore throats is reduced. The main peak value of the pore throat radius of the pore throat mercury entry and permeability contribution value is between 0.1 and $0.5 \mu \mathrm{m}$, and the connectivity between the pore throats is poor. The physical properties of the reservoir are relatively poor, with an average porosity of $7.99 \%$ and an average permeability of $0.35 \times 10^{-3} \mu \mathrm{m}^{2}$, respectively. The quality of the reservoir is poor, and it is a poor diagenetic facies belt in the study area (Table 2, Fig. 6a).

(4) Carbonate cemented tight diagenetic facies.

The main diagenetic feature is the pore-filling cementation and metasomatism of the iron-calcite-based continuous crystal carbonate, which leads to the loss of primary intergranular pores and the lack of dissolution (Fig. 5d). Carbonate cements reduce the intergranular pore space and cause greater damage to the reservoir, which is one of the most important reasons for the decrease in reservoir porosity in the study area. The average rock density in this diagenetic facies belt is $2.57 \mathrm{~g} / \mathrm{cm}^{3}$, and the average interstitial volume 
content is $14.95 \%$. The pore combination is dominated by micropores, the high-pressure mercury intrusion threshold pressure is high, and the distortion is fine. It shows that the pore throats are poorly sorted, the median radius is small, and the pore throats have almost disappeared. The unimodal shape is the main shape of the pore throat radius distribution and permeability contribution curve. The contribution rate of permeability and the amount of mercury in the pore throat are the least, the main peak is mainly distributed at $<0.1 \mu \mathrm{m}$, and the connectivity is poor. The physical properties of the reservoir are the worst, with an average porosity of $5.37 \%$ and an average permeability of $0.18 \times 10^{-3} \mu \mathrm{m}^{2}$, which are relatively poor diagenetic facies belts in the study area, and are almost ineffective reservoirs (Table 2, Fig. 6a).

In the initial stage of the mercury intrusion experiment, for samples with different permeability, the relatively large pore throat occupies a small proportion, but the cumulative permeability contribution value rises rapidly to about $98 \%$ within the radius of the large pore throat. The cumulative mercury saturation in this interval is also increasing rapidly, and the curve is relatively steep, but the degree of steepness is not as steep as the cumulative permeability contribution rate. The cumulative mercury saturation reached in this interval is mainly distributed between 49 and 66\% (Fig. 6). Subsequently, mercury continued to enter the sample, and the cumulative permeability contribution curve showed a flat trend with a slow increase rate, while the cumulative mercury saturation increase rate did not decrease significantly. It shows that the relatively large pore throat mainly controls the permeability, and the relatively small pore throat has little influence on the permeability, but has a certain storage capacity. Through analysis of mercury intrusion samples in the study area, it was found that the average mercury saturation of about $29.5 \%$ was controlled by relatively small pore throats. The permeability of the study area is mostly controlled by pore throats with a radius larger than $R_{50} \sim R_{60}$.

\section{Pore evolution characteristics of different diagenetic facies types}

Through the porosity evolution simulation equations of formulas 1-7 in Table 3, the diagenetic evolution characteristics of the four different diagenetic facies types in the study area are analyzed. The initial porosities of the four diagenetic facies in the study area were 37.01, 37.05, 36.69, and $36.88 \%$ (Fig. 7). According to the calculation results of the initial porosity of different diagenetic facies, it is found that although the four diagenetic facies belts have different grain structures and sorting characteristics, the initial porosities are relatively similar. It shows that the characteristics of clastic particles during the deposition process are not the main factor that causes the current decline in reservoir quality.

After the early compaction, the porosity of the four diagenetic facies has been significantly lost, and the differences between them are gradually obvious. The porosities of the four diagenetic facies after compaction are 19.32, 17.15, 17.08, and $25.43 \%$ (Fig. 7). The compaction caused the smallest loss of porosity of the carbonate cemented tight diagenetic facies, indicating that the carbonate cementation of the grain surface structure has obvious resistance to mechanical compaction. The porosity of the four diagenetic facies was further destroyed due to cementation. The porosity after the early cementation was $15.03,13.26,13.21$, and $8.31 \%$, respectively, and the porosity after the middle and late cementation was $12.28,10.15,7.81$, and $4.98 \%$, respectively (Fig. 7). The dissolution of the four diagenetic facies increases the porosity. It can be seen that the dissolution of the feldspar dissolution phase increases the porosity the highest at $3.95 \%$, followed by

Table 3 Quantitative calculation method of sandstone porosity evolution

\begin{tabular}{|c|c|c|}
\hline Porosity evolution parameter & Formula & Remarks \\
\hline Initial porosity & $\Phi_{1}=20.91+22.9 / S_{\mathrm{d}}$ & $\begin{array}{l}\Phi_{1} \text { represents the original porosity of the unconsolidated sandstone, } \% ; S_{\mathrm{d}} \\
\text { represents the Trask sorting coefficient, } S_{\mathrm{d}}=\left(P_{25} / P_{75}\right)^{1 / 2} \text { (in which } P_{25} \text { and } P_{75} \\
\text { represent the corresponding granular diameter of } 25 \% \text {-in-content particles and } \\
75 \% \text {-in-content particles in the accumulative granularity curve respectively, } \\
\mathrm{mm})\end{array}$ \\
\hline Porosity after compaction & $\begin{array}{l}\Phi_{2}=C+\left(P_{1}+P_{2}\right) \times P_{3} / P_{4} \\
\quad F \mathrm{a}=\left(\Phi_{1}-\Phi_{2}\right) / \Phi_{1}\end{array}$ & $\begin{array}{l}\Phi_{2} \text { represents the porosity after compaction, } \% ; C \text { represents the cement content, } \\
\% ; P_{1} \text { represents the surface porosity of intergranular pores, } \% ; P_{2} \text { represents the } \\
\text { surface porosity of original micro pores, } \% ; P_{3} \text { represents the measured porosity } \\
\text { of the sample, } \% ; P_{4} \text { represents the total surface porosity, } \% ; P_{\mathrm{a}} \text { represents the } \\
\text { porosity loss due to compaction, } \% ; F_{\mathrm{a}} \text { represents the ratio of porosity loss due } \\
\text { to compaction, } \%\end{array}$ \\
\hline Porosity after cementation & $\begin{array}{l}\Phi_{3}=\Phi_{2}-C \\
F \mathrm{~b}=\left(\Phi_{2}-\Phi_{3}\right) \times 100 \% / \Phi_{1}\end{array}$ & $\begin{array}{l}\Phi_{3} \text { represents the porosity after compaction and cementation, } \% ; F_{\mathrm{b}} \text { represents the } \\
\text { ratio of porosity loss due to cementation, \% }\end{array}$ \\
\hline Dissolution increases porosity & $\begin{array}{l}\Phi_{4}=P_{5} \times P_{3} / P_{4} \\
F \mathrm{c}=\Phi_{4} \times 100 \% / \Phi_{1}\end{array}$ & $\begin{array}{l}\Phi_{4} \text { represents the increased porosity due to dissolution, } \% ; P_{5} \text { represents the total } \\
\text { dissolution pore surface area, } \% ; F_{\mathrm{c}} \text { represents the ratio of porosity loss due to } \\
\text { dissolution, } \%\end{array}$ \\
\hline
\end{tabular}


Fig. 7 Pore evolution process of different diagenetic facies

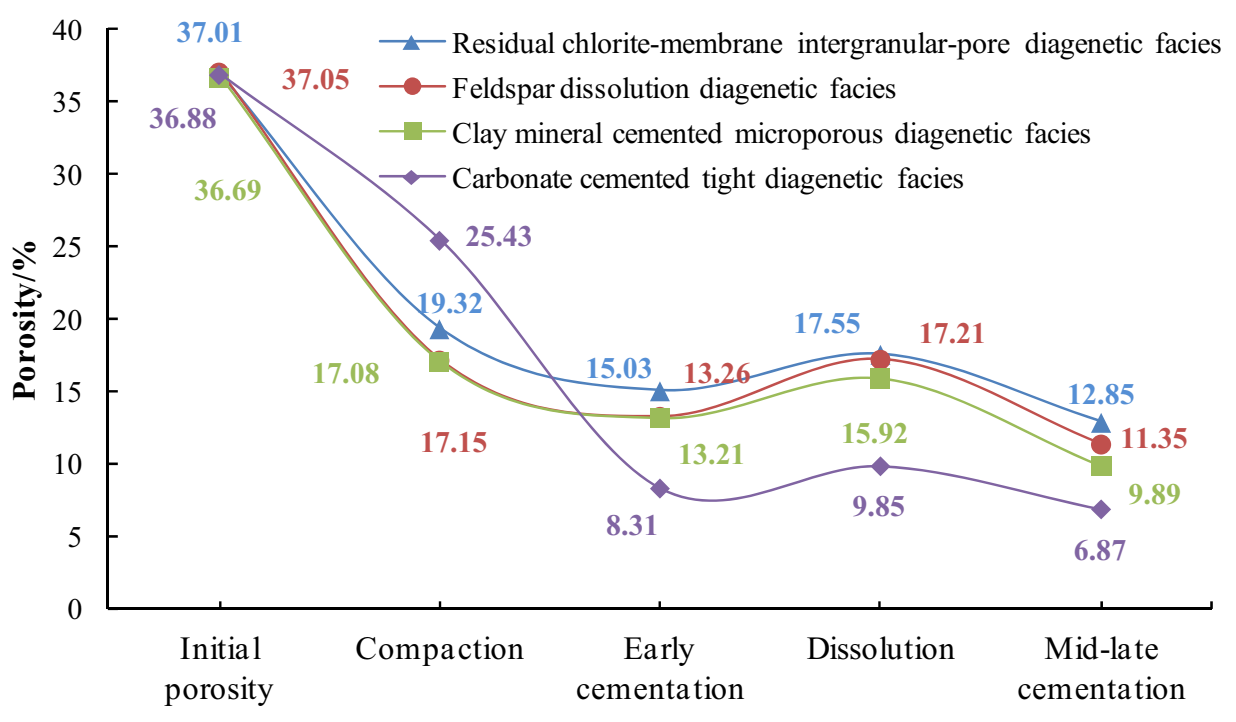

the clay mineral cemented microporous phase and the remaining intergranular pore phase of the chlorite membrane. Carbonate cemented tight diagenetic facies dissolution increases the lowest porosity (Fig. 7).

Through the analysis of diagenetic evolution, it is found that a large number of minerals and fluids continuously compact, fill pores, and dissolve particles in the pore space of the sediment. However, the impact of different diagenesis in different regions and environments is also different. This can be proved by the porosity evolution characteristics of diagenetic facies. The final calculated porosity of residual chlorite-membrane intergranular-pore diagenetic facies is the largest, which is $12.28 \%$. Feldspar dissolution diagenetic facies increased the most, with an average of $3.95 \%$. Clay mineral cemented microporous diagenetic facies lost the most porosity due to the middle and late cementation, with an average of $8.11 \%$. Carbonate cemented tight diagenetic facies leads to the least loss of porosity, while the early cementation leads to the largest loss of porosity, which is $17.12 \%$.

\section{Classification evaluation of reservoir quality}

\section{Quantitative characterization of micro-heterogeneity}

The microscopic heterogeneity of sandstone reservoirs is mainly caused by the combination of sedimentation and diagenesis. The grain size and sorting of sandstone are mainly controlled by sedimentation, which determines the initial porosity of the reservoir. The compaction, cementation, and dissolution experienced during the diagenesis process eventually resulted in the strong micro-heterogeneity of the sandstone reservoirs in the study area. Therefore, it is necessary to introduce the heterogeneity parameter of the pore throat structure to reflect the diversity and complexity of the pore structure, which is also the key parameter of this evaluation. Three parameters, standard deviation of particle size, comprehensive index of diagenesis and fractal dimension of pore structure were selected to characterize the influence of sedimentation, diagenesis and pore throat structure on micro-heterogeneity. Among them, the particle size standard deviation $\sigma$ is the main parameter reflecting the heterogeneity of rock particles, the pore filling index mainly considers the degree of cementation and the degree of feldspar undissolved, and the fractal dimension of pore structure is mainly calculated by the relevant parameters of the capillary pressure curve. The larger the values of the three types of parameters are, the stronger the heterogeneity caused (see Table 4 for related calculation formulas). Based on the research of the three types of parameters that characterize heterogeneity, the micro-heterogeneity evaluation index $\mathrm{M}$ is established to reflect the strength of micro-heterogeneity. Among them, $M=\sigma \times P \times D$, the larger the index, the stronger the heterogeneity of the microscopic pore structure. This index can better characterize the degree of micro-heterogeneity, reflect the characteristics of reservoir seepage, predict the distribution of remaining oil, and provide certain guidance for oilfields to formulate water injection development plans.

\section{Comprehensive quantitative classification and evaluation of reservoirs}

Use the method of multiple comprehensive classification coefficients to systematically make reasonable classification 
Table 4 Calculation method of micro-heterogeneity of tight sandstone [22,23](Zhu 2008; Ma, et al. 2005)

\begin{tabular}{|c|c|c|}
\hline Parameter & Calculation formula & Remarks \\
\hline Particle size standard deviation $(\sigma)$ & $\left(\left({ }_{84}-{ }_{16}\right) / 4\right)+\left(\left({ }_{96}-{ }_{5}\right) / 6.6\right)$ & $\begin{array}{l}\Phi_{84}, \Phi_{16}: \text { Middle of the size distribution interval; } \\
\Phi_{96}, \Phi_{5}: \text { Two endpoints of the size distribution interval }\end{array}$ \\
\hline Pore filling index $(\mathrm{P})$ & $(C /(C+I)) \times\left(F /\left(F+F_{\mathrm{d}}\right)\right)$ & $\begin{array}{l}\text { C: Cement content; I: Intergranular pores rate; } \\
\text { F: Feldspar content; } F_{d} \text { : The dissolution pore rate of feldspar }\end{array}$ \\
\hline Fractal dimension of pore structure(D) & $\begin{array}{l}(\lg S \mathrm{w}-3(\lg P \min -\lg P \mathrm{c})) \\
\quad /(\lg P \mathrm{c}-\lg P \min )\end{array}$ & $\begin{array}{l}\text { Sw: Mercury saturation at Pc pressure; } \\
\text { Pc: The capillary pressure corresponding to any pore radius; } \\
\text { Pmin: capillary pressure corresponding to maximum pore radius }\end{array}$ \\
\hline Micro-heterogeneity evaluation index $(M)$ & $M=\sigma \times \mathrm{P} \times \mathrm{D}$ & $\begin{array}{l}\text { The greater the index, the stronger the heterogeneity of micro- } \\
\text { scopic pore structure }\end{array}$ \\
\hline
\end{tabular}

evaluations from multiple angles, ensuring the quantification and rationalization of the results of this reservoir evaluation. First of all, porosity and permeability directly reflect the storage and seepage capacity of the reservoir, so they occupy the primary position in reservoir evaluation. Secondly, when selecting each influencing parameter, the parameters should be optimized based on the principles of practicability, representativeness, discreteness and relevance. By analyzing the main influencing factors of reservoir quality, nine parameters are finally selected for the next quantitative evaluation: porosity, permeability, reservoir quality factor $\left(\sqrt{\frac{K}{\Phi}}\right)$, clay mineral content, carbonate content, porosity, drainage pressure, average pore throat radius, micro-heterogeneity evaluation index.

By analyzing the relationship between these nine parameters and reservoir quality, it is concluded that porosity, permeability, reservoir quality factor, borehole ratio and average pore throat radius are positively correlated with reservoir quality - the larger the parameter value, the greater the better the reservoir. The clay mineral content, carbonate content, displacement pressure and heterogeneity evaluation index are negatively correlated with the performance of the reservoir-the larger the parameter, the worse the reservoir. Using the method of multiple classification coefficients to normalize each parameter, the calculation formula is as follows:

$F_{\text {eci }}=\ln \frac{\frac{\Phi_{i}}{\Phi_{\max }} \times \frac{K_{i}}{K_{\max }} \times \frac{\mathrm{RQI}_{i}}{\mathrm{RQI}_{\max }} \times \frac{C_{i}}{C_{\max }} \times \frac{\bar{R}_{i}}{\bar{R}_{\max }}}{\frac{\mathrm{CLM}_{i}}{\mathrm{CLM}_{\max }} \times \frac{\mathrm{CAM}_{i}}{\mathrm{CAM}_{\max }} \times \frac{P \mathrm{c}_{i}}{P \mathrm{c}_{\max }} \times \frac{M_{i}}{M_{\max }}}$

In the formula, $F_{\text {eci }}$ is the multivariate comprehensive classification coefficient; $\Phi$ is the porosity, $\%$; $\mathrm{K}$ is the permeability, $\times 10^{-3} \mu \mathrm{m}^{2}$; RQI is the reservoir quality factor, $\mu \mathrm{m} ; C$ is the face ratio, $\% ; \bar{R}$ is the average pore throat radius, $\mu \mathrm{m}$; CLM is the clay mineral content, \%; CAM is the carbonate content, $\% ; P_{\mathrm{c}}$ is the displacement pressure, $\mathrm{MPa} ; \mathrm{M}$ is the heterogeneity evaluation index; the index $\mathrm{i}$ is a single specific parameter; max is the largest of the parameters value.

The multivariate comprehensive classification coefficient integrates the nine parameters that affect the quality of the reservoir in the study area from multiple perspectives, and quantitatively characterizes the comprehensive quality of the reservoir. According to the calculation results of the multivariate comprehensive classification coefficient method, the tight sandstone reservoirs in the study area are divided into 4 types: Type I: Feci $>7$; Type II: $3<$ Feci $\leq 7$; Type III: $-2<$ Feci $\leq 3$; Type IV: Feci $\leq-2$.

The multivariate comprehensive classification coefficient method can classify the reservoir quantitatively, and the result is more accurate. It has a good effect on the classification and evaluation of tight sandstone reservoirs in the study area. However, if we want to make more accurate reservoir classification evaluation and prediction of planar distribution of more than 700 wells in the whole area, we need to find methods or parameters that are closely related to the multivariate comprehensive classification coefficient method and have strong coverage. The diagenetic facies has a close relationship with the multivariate comprehensive classification coefficient $F_{\text {eci }}$, and the reservoir types classified by $F_{\text {eci }}$ have a good corresponding relationship with the diagenetic facies (Fig. 8), indicating that diagenetic facies can well reflect the characteristics of the multivariate comprehensive classification coefficient. Therefore, the quantitative characterization of diagenetic facies logging can be used to predict the reservoir classification in the whole area.

\section{Quantitative identification of diagenetic facies logging}

The differences between different diagenetic facies are mainly manifested in rock structure, cement composition, diagenetic strength, pore structure characteristics, physical 


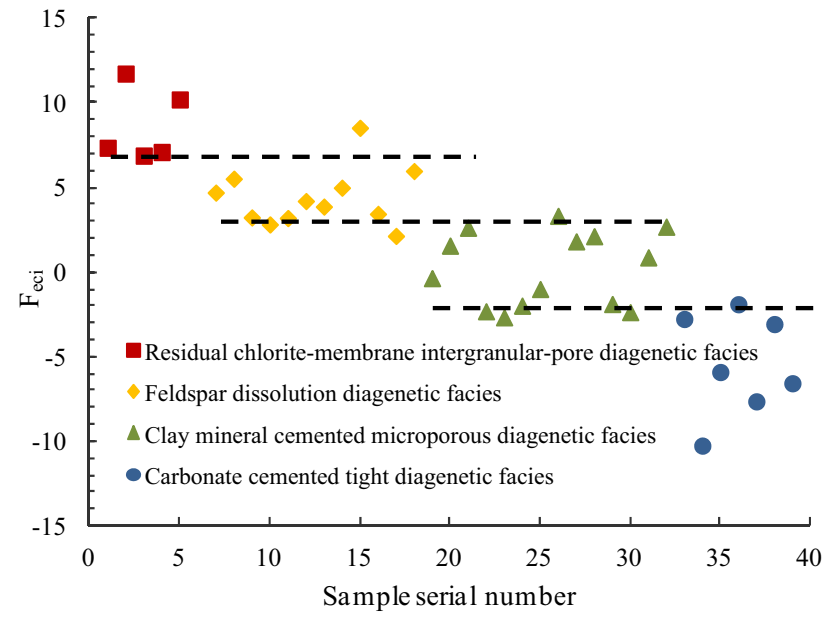

Fig. $8 F_{\text {eci }}$ coefficient distribution characteristics of different diagenetic facies

properties, etc. Therefore, it is necessary to use logging data to analyze the difference between different diagenetic characteristics and logging responses to achieve the purpose of identifying diagenetic facies. In general, the density, neutrons, acoustic jet lag, natural gamma, and resistivity in the logging curve are more sensitive to the response of diagenetic facies (Shi et al. 2011).

The compaction causes a substantial compression of the pore space. In the area where the degree of compaction is stronger, the contact relationship between particles is relatively closer, and the content of plastic minerals and shale is relatively higher. The response characteristics on the logging curve generally show that the greater the density, neutrons and natural gamma, the lower the acoustic interval transit time. Cementation causes the pore space to be filled, resulting in increased density and decreased acoustic interval transit time. Natural gamma, neutrons, and resistivity will have different trends depending on the cement. Among them, carbonate minerals are non-conductive, usually not radioactive, and have a low hydrogen index, so they often have high resistivity, low natural gamma and neutrons. The influence of siliceous bonding on the logging curve is mainly manifested as medium high density, medium low acoustic interval transit time, medium low resistivity, and low natural gamma. Clay minerals often adsorb radioactive substances, increase the volume of bound water, and have a relatively high hydrogen index. Therefore, logging curves generally show relatively high values of natural gamma and neutrons, and relatively low values of resistivity. The main result of dissolution is the generation of secondary pores. Therefore, the log parameter density and neutron response that reflect the total porosity have an obvious relationship with the response, which mainly manifests as a decrease in density and an increase in neutrons. The acoustic interval transit time mainly reflects the original porosity, so there is no obvious response characteristic.

\section{Conventional intersection diagram method}

According to the difference in logging parameter density, neutron, natural gamma and acoustic time difference, which are more sensitive to different diagenetic facies, establish mutual intersection diagrams, in order to directly and quantitatively identify the boundaries of different diagenetic facies through the intersection diagram of logging parameters (Fig. 9). From the four intersection diagrams, it can be found that the degree of distinction between density and sonic jet lag is relatively good, but there is still some overlap. The remaining three intersection maps have relatively large overlaps, indicating that the logging curves in the study area cannot accurately and quantitatively divide the diagenetic facies. Therefore, it is necessary to further introduce a new method-Fisher discriminant method to achieve more accurate quantitative identification of diagenetic facies logging.

\section{Fisher discriminant method}

The basic idea of the Fisher discriminant analysis method is projection. By finding a projection matrix, mapping the multi-dimensional data points to the low-dimensional space, and then optimizing the most suitable projection direction by analyzing the variance, the total data volume can be divided as much as possible with different types. Then construct the discriminant function, and then realize the quantitative recognition of the sample type (Xu 2000). Fisher discriminant method is often used in fluid identification and lithology identification, and has achieved more obvious results (Zhang et al. 2018; Luo et al. 2013; Wang et al. 2017). The specific process is as follows: (1) based on Fisher's dimensionality reduction idea, calculate the sensitive logging curves that reflect the different diagenetic facies optimized in the previous article. (2) According to the calculated contribution rate of the variance of eigenvalues, determine and construct the intersection chart of the main factor and the minor factor that can identify the diagenetic facies. (3) According to the optimization algorithm, the discriminant function of different diagenetic facies is constructed. (4) Finally, the maximum value calculated by the diagenetic facies discriminant function of the unknown sample is the final result of diagenetic facies identification (Fig. 10).

The four sensitive logging parameters of natural gamma, neutron, density and acoustic time difference at 136 sample points in the study area are used as the main analysis parameters. And according to the Fisher discriminant analysis method, the eigenvalues and variance contribution rates of the three canonical discriminant functions were obtained. Among them, the first canonical discriminant 

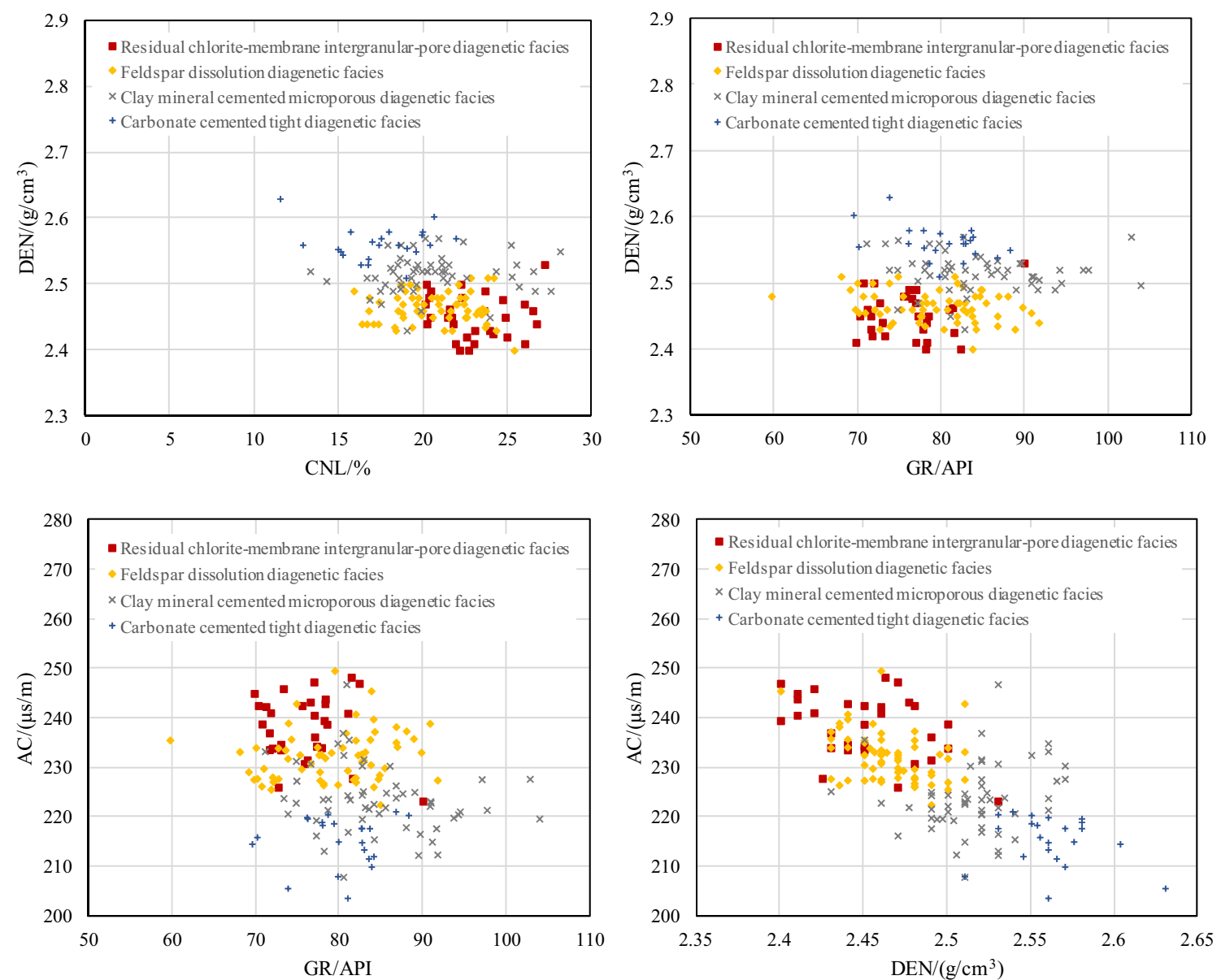

Fig. 9 Intersection of diagenetic facies logging curves

function obtained by calculation is the main factor, the second canonical discriminant function is a secondary factor, and the third canonical discriminant function has little influence on the final discriminant result, and is then discarded. The formulas are:

$$
\begin{aligned}
\text { Main factor }= & -0.140 \mathrm{AC}+35.140 \mathrm{DEN} \\
& -0.046 \mathrm{CNL}+0.041 \mathrm{GR}-58.001
\end{aligned}
$$

Secondary factor $=-0.025 \mathrm{AC}+3.899 \mathrm{DEN}$

$$
+0.186 \mathrm{CNL}+0.148 \mathrm{GR}-31.166
$$

In the formula, $\mathrm{AC}$ is the acoustic interval transit time, $\mu \mathrm{s} / \mathrm{m}$; DEN is the density, $\mathrm{g} / \mathrm{cm}^{3}$; CNL is the neutron, \%; GR is the natural gamma, API.

Through the intersection diagram of the primary and secondary factors (Fig. 11), it is found that compared with the conventional intersection diagram method, the Fisher discriminant method improves the accuracy of diagenetic facies logging identification, and the boundaries of the four diagenetic facies types are clearer.

Then, through the logging interpretation software analysis, the discriminant functions of the four diagenetic facies are obtained. Use the discriminant function to identify the corresponding logging parameters of unknown diagenetic facies samples. The discriminant functions of the four diagenetic facies are:

$$
\begin{aligned}
\mathrm{F}_{1}= & 10.266 \mathrm{AC}+4941.647 \mathrm{DEN} \\
& -8.911 \mathrm{CNL}+4.532 \mathrm{GR}-7335.294
\end{aligned}
$$

$\mathrm{F}_{2}=9.840 \mathrm{AC}+5012.076 \mathrm{DEN}-9.188 \mathrm{CNL}+4.623 \mathrm{GR}-7408.414$

$\mathrm{F}_{3}=9.423 \mathrm{AC}+5135.687 \mathrm{DEN}-9.158 \mathrm{CNL}+4.860 \mathrm{GR}-7641.87$

$\mathrm{F}_{4}=9.009 \mathrm{AC}+5241.913 \mathrm{DEN}-9.467 \mathrm{CNL}+4.791 \mathrm{GR}-7810.051$

In the formula, $F_{1}$ is the residual chlorite-membrane intergranular-pore diagenetic facies; $\mathrm{F}_{2}$ is the feldspar dissolution diagenetic facies; $F_{3}$ is the clay mineral cemented 


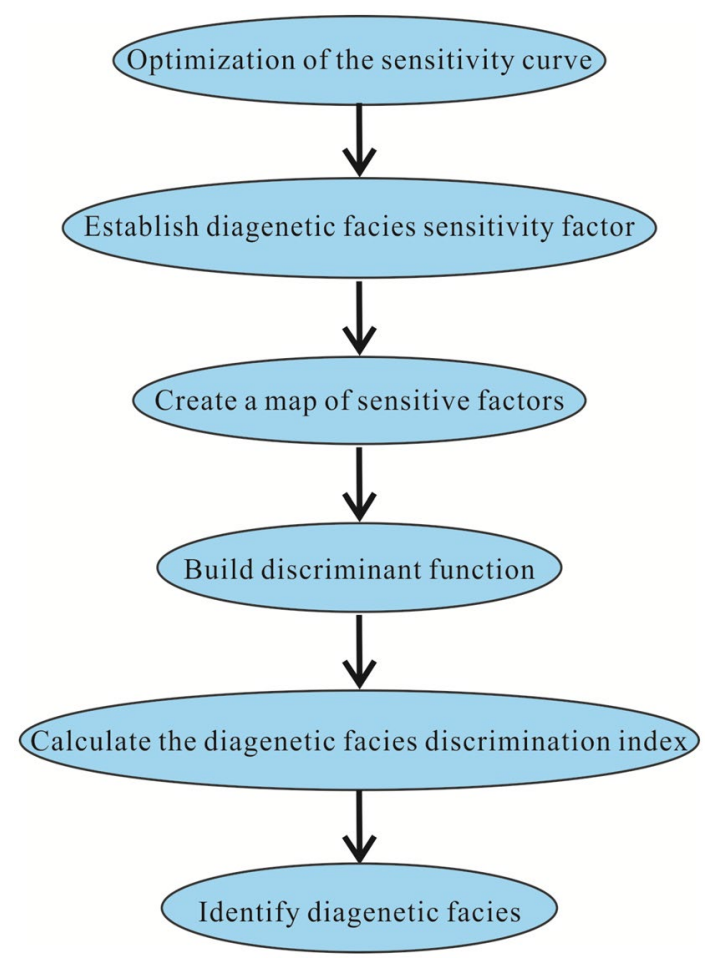

Fig. 10 The flowchart of Fisher discriminant method to identify diagenetic facies

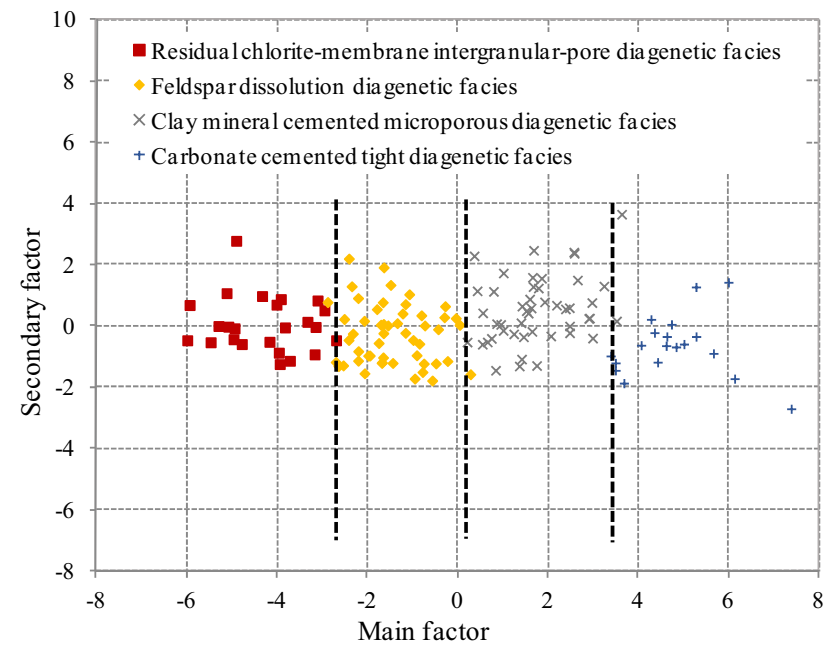

Fig.11 Intersection diagram of major factors and minor factors

microporous diagenetic facies; $\mathrm{F}_{4}$ is the carbonate cemented tight diagenetic facies.

For unknown diagenetic facies types, the corresponding logging parameter values are, respectively, brought into the discriminant function formula 4.3-4.6, and the discriminant function values of the four diagenetic facies are calculated. Then, after comparing, the discriminant function type where the maximum value is located is the type of diagenetic facies.

\section{Application effect analysis}

Through log curve analysis and calculation of nearly 317 wells in the study area, the diagenetic facies were identified and compared with the corresponding depth section results to verify the accuracy of the diagenetic facies log identification results of the Fisher discriminant method. From the comparative analysis of the diagenetic facies identification results of Well H206 and the thin section identification results (Fig. 12), it is found that the remaining intergranular pore diagenetic facies of the chlorite membrane develops between $2028 \mathrm{~m}$ and $2031.4 \mathrm{~m}$. Corresponding to the observation under the microscope in the casting thin section experiment at $2029 \mathrm{~m}$, the intergranular pores are developed and the edges of the particles are wrapped with a chlorite film. The feldspar dissolution diagenetic facies developed at 2031.4-2033.8 m, corresponding to the observation of feldspar dissolution under the experimental microscope of $2033 \mathrm{~m}$ scanning electron microscope. Carbonate cemented compact diagenetic facies developed at 2049.6-2052 m, corresponding to the observation of carbonate cementation and metasomatism under the cathodoluminescence experimental microscope at $2050.2 \mathrm{~m}$, and the pores were not developed. Clay mineral cemented microporous diagenetic facies developed at 2054-2055.5 m, corresponding to the observation of illite and chlorite cemented and filled pores in the scanning electron microscope experiment at $2055.1 \mathrm{~m}$. The result of diagenetic facies identification is in good agreement with the minerals and pores in the thin section, indicating that the Fisher discriminant analysis method has a relatively good effect on the identification of diagenetic facies. On this basis, the planar distribution of diagenetic facies in the whole area was compiled with dominant facies in small layers (Fig. 13).

\section{Conclusions}

(1) The study area has undergone strong diagenetic transformation. The average porosity loss rate caused by compaction is $50.62 \%$, the overall porosity loss rate caused by cementation is about $27.8 \%$, and the secondary porosity increased by dissolution is $2.26 \%$ on average. The overall porosity is strongly damaged by compaction and middle and late cementation, resulting in significant differences in the porosity evolution characteristics, physical properties, and microscopic pore throat radius distribution characteristics of the four types of diagenetic facies (residual chlorite-membrane intergranular-pore diagenetic facies, feldspar dissolu- 


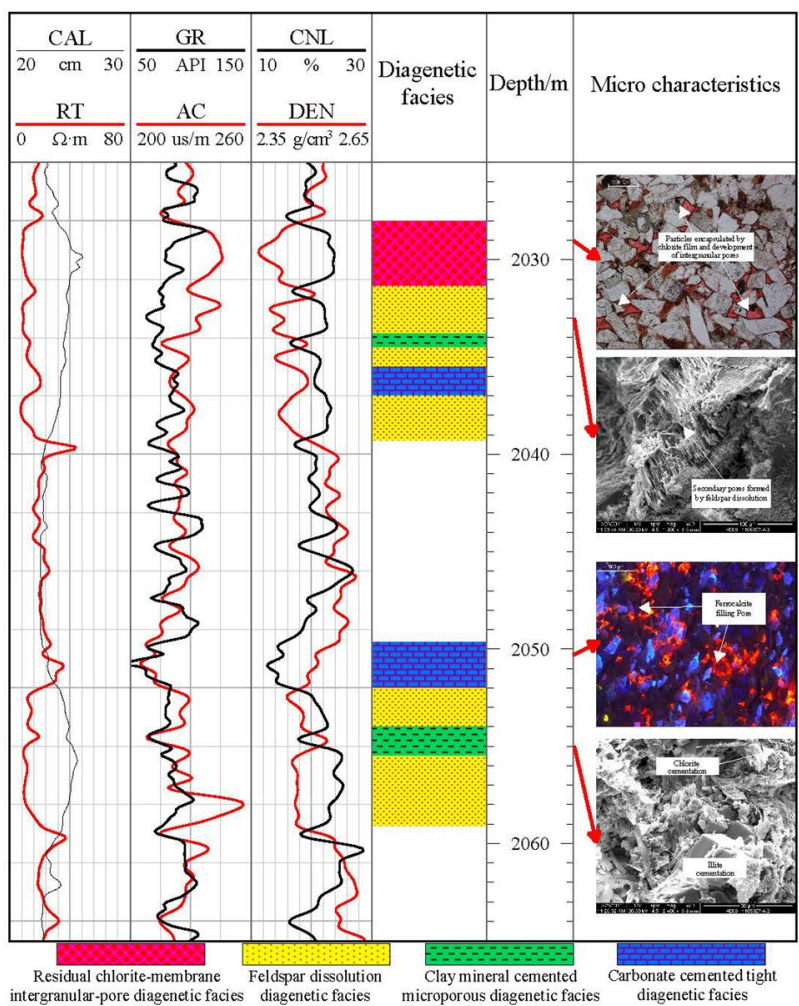

Fig.12 Log identification results of H206 diagenetic facies

tion diagenetic facies, clay mineral cemented microporous diagenetic facies, carbonate cemented tight diagenetic facies) in the study area. It has a good reflection on the quality of the reservoir.

(2) Using the method of multivariate comprehensive classification coefficient, the study area is divided into four categories quantitatively from multiple perspectives: Type I: $\mathrm{F}_{\text {eci }}>7$; Type II: $3<\mathrm{F}_{\text {eci }} \leq 7$; Type III: $-2<\mathrm{F}_{\text {eci }} \leq 3$; Type IV: $\mathrm{F}_{\text {eci }} \leq-2$. Diagenesis facies has a good corresponding relationship with the multivariate comprehensive classification evaluation coefficient $\mathrm{F}_{\text {eci }}$ of the reservoir, indicating that diagenesis has a good characterization effect relative to the quality of the reservoir.

(3) The Fisher discriminant analysis method is used to distinguish the log response characteristics of different diagenetic facies, and an intersection chart of the primary and secondary factors with good distinguishability is constructed. Furthermore, the discriminant function of diagenetic facies logging curves is established, which can quantitatively identify different diagenetic facies types in the study area, and has achieved good application effects. The quantitative characterization of reservoir classification prediction from samples (points) to well positions (surfaces) in the whole area

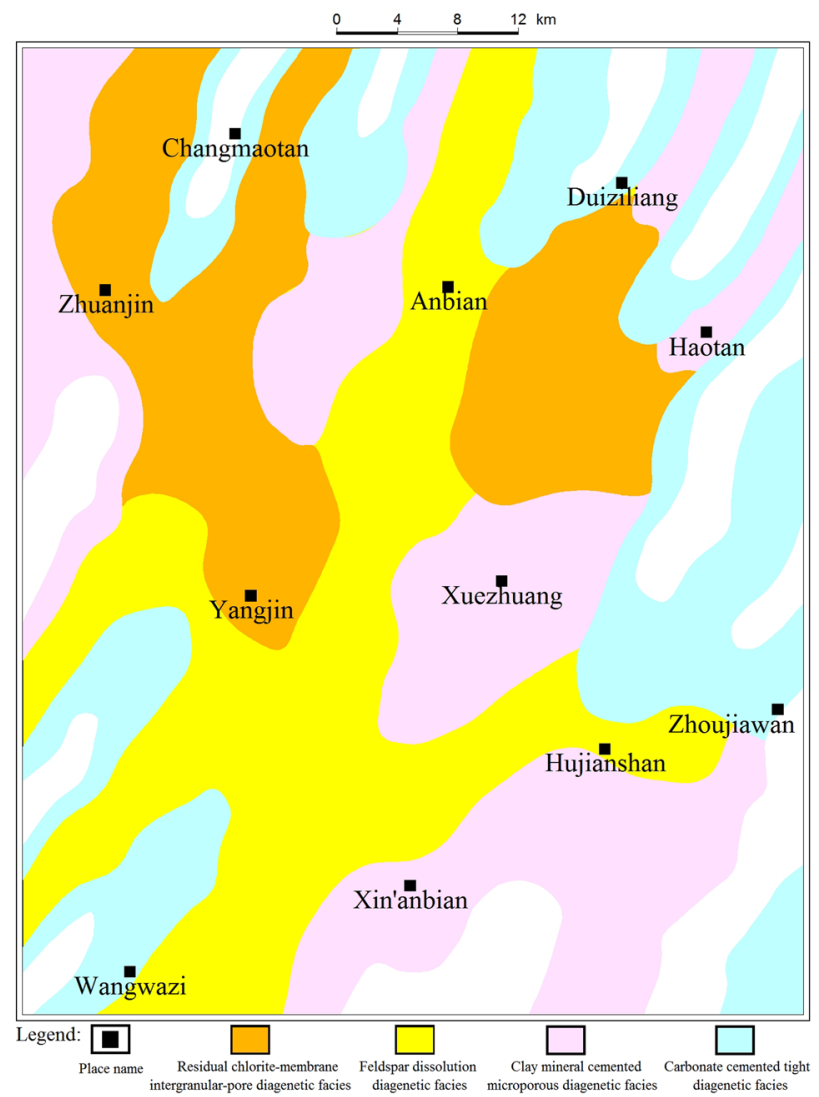

Fig. 13 Plane distribution pattern of diagenetic facies

is realized, which is very important for the current oil and gas exploration and development.

Acknowledgements Thank all members of the team for their efforts. This work is funded by National Science and Technology Major Project of the Ministry of Science and Technology of China (2017ZX05013004; 2017ZX05069-003).

Funding National Science and Technology Major Project of the Ministry of Science and Technology of China (2017ZX05013-004; 2017ZX05069-003).

\section{Declarations}

Conflict-of-interest On behalf of all authors, Shi Jian states that there is no conflict of interest.

Open Access This article is licensed under a Creative Commons Attribution 4.0 International License, which permits use, sharing, adaptation, distribution and reproduction in any medium or format, as long as you give appropriate credit to the original author(s) and the source, provide a link to the Creative Commons licence, and indicate if changes were made. The images or other third party material in this article are included in the article's Creative Commons licence, unless indicated otherwise in a credit line to the material. If material is not included in the article's Creative Commons licence and your intended use is not 
permitted by statutory regulation or exceeds the permitted use, you will need to obtain permission directly from the copyright holder. To view a copy of this licence, visit http://creativecommons.org/licenses/by/4.0/.

\section{References}

Deng XQ, Lin FX, Liu XY, Pang JL, Lv JW, Li SX, Liu X (2008) Discussion on relationship between sedimentary evolution of the Triassic Yanchang Formation and the Early Indosinian Movement in Ordos Basin. Journal of Palaeogeography 5(2):159-166

Frebch MW, Worden RH, Mariani E (2012) Microcrystalline quartz generation and the preservation of porosity in sandstones: Evidence from the Upper Cretaceous of the Subhercynian Basin. Germany Journal of Sedimentary Research 82(6):422-434

Fu J, Wu SH, Fu JH, Hu LQ, Zhang HF, Liu X (2013) Research on quantitative diagenetic facies of the Yanchang Formation in Longdong Area. OrdosBasin Earth Science Frontiers 20(3):86-97

Fu, J. H., Guo, Z. Q., Deng X. Q., Sedimentary facies of the Yanchang Formation of Upper Triassic and petroleum geological implication in southwestern Ordos Basin. Journal of Palaeogeography 7(1): 34-44.

Guo QL, Wu N, Chen NS, Ren HJ, Yang Z, Xie HB (2017) An assessment of tight oil resource in 7th oil reservoirs of Yanchang Formation. Ordos Basin Acta Petrolei Sinica 38(6):658-665

Lai J, Wang GW, Huang LX, Guan B, Jiang C, Ran Y, Zhang XT, Li M, Wang D (2015) Quantitative classification and logging identification method for diagenetic facies of tight sandstones. Bulletin of Mineralogy, Petrology and Geochemistry 34(1):128-138

Li JW, Tian JC, Chen HD, Xiao L (2006) Characteristics of sedimentary microfacies in Chang 6 oil-bearing formation of Yanchang formation in Hujianshan-Gengwan area. Ordos Basin Xinjiang Geology 24(4):437-440

Li SX, Deng XQ, Pang JL, Lv JW, Liu X (2010) Relationship between petroleum accumulation of Mesozoic and tectonic movement in Ordos Basin. Acta Sedimentol Sin 28(4):798-807

Li XB, Liu XY, Zhou SX, Liu HQ, Chen QL, Wang J, Liao JB, Huang JP (2012) Hydrocarbon origin and reservoir forming model of the Lower Yanchang Formation. Ordos Basin Petroleum Exploration and Development 39(2):172-180

Liao P, Tang J, Pang GY, Tang L, Ma XF, Wang Q (2012) Reservoir characteristics and control factors of Chang $8_{1}$ of Yanchang Formation of Triassic in Jiyuan region of Ordos Basin. Journal of Mineralogy and Petrology 32(2):97-104

Luo DJ (2013) The method on the fluid identification of rock elastic properties by Fisher Discriminant Analysis in fragmental rock. Prog Geophys 28(4):1919-1924

Ma XF, Zhang SC, Lang ZX (2005) Fractal characterization of characteristic parameters of pore structure. Petroleum Geology and Recovery Efficiency 12(6):16-29

Maas TE, Jahren J, Bjørlykke K (2011) Diagenetic controls on reservoir quality in Middle to Upper Jurassic sandstones in the South Viking Graben. North Sea AAPG Bulletin 95(11):1937-1958
Morad S, Al-Ramadan K, Ketzer JM, De Ros LF (2010) The impact of diagenesis on the heterogeneity of sandstone reservoirs: A review of the role of depositional facies and sequence stratigraphy. AAPG Bull 94(8):1267-1309

Shi YJ, Xiao L, Mao ZQ, Guo HP (2011) An identification method for diagenetic facies with well logs and its geological significance in low permeability sandstones: A case study on Chang 8 reservoirs in the Jiyuan region. Ordos Basin Acta Petrolei Sinica 32(5):820-827

Taylor TR, Giles MR, Hathon L, Diggs TN (2010) Sandstone diagenesis and reservoir quality prediction: models, myths and reality. AAPG Bull 94(8):1093-1132

Wang F, Tian JC, Zhang JQ, Ni XF, Xia QS, Nie YS (2006) Provenance analysis of the Chang- 6 pay sets of the Yanchang Formation in the west-central parts of the Ordos Basin. Sedimentary Geology and Tethyan Geology 3:26-30

Wang P, Hu XY, Wei SJ (2017) Lithologic Identification of Complex Reservoirs Based on Kernel Fisher Discriminant Analysis. Science Technology and Engineering 17(31):29-34

Xu SY (2000) Comprehensive log interpretation and evaluation of low resistivity reservoirs for SQ oil field. Pet Explor Dev 27(6):74-76

Yang H, Li SX, Liu XY (2013) Characteristics and resource prospects of tight oil and shale oil in Ordos Basin. Acta Petrolei Sinica 34(1):1-11

Yang YT, Li W, Ma L (2005) Tectonic and stratigraphic controls of hydrocarbon systems in the Ordos basin: a multicycle cratonic basin in central China. AAPG Bull 89(2):255-269

Zhang SH, Shi YJ, Chen G, Zhou JY, Guo HP, Wang CS, Sun JF, Li WB, Zhong JB, Gao JY, Qu YL (2018) Identification methods and water productivity classification evaluation of low contrast Chang $6_{1}$ oil reservoirs in Jiyuan area. Ordos Basin China Petroleum Exploration 23(1):71-80

Zhang XX, Zou CN, Zhu RK, Tao SZ, Yang SS (2011) Reservoir diagenetic facies of the upper Triassic Xujiahe formation in the central Sichuan Basin. Acta Petrolei Sinica 32(2):257-264

Zhu, X. M., 2008. Sedimentary petrology. Petroleum Industry Press.

Zou CN, Tao SZ, Xue SH (2005) Connotation of "Fades Control Theory" and its significance for exploration. Pet Explor Dev 32(6):7-12

Zou CN, Hou LH, Kuang LC, Kuang J (2007) Genetic mechanism of diagenesis reservoir facies of the fan-controlled premotriassic in the western marginal area. Junggar Basin Chinese Journal of Geology 42(3):587-601

Zou CN, Tao SZ, Zhou H, Zhang XX, He DB, Zhou CM, Wang L, Wang XS, Li FH, Zhu RK (2008) Genesis, classification and evaluation method of diagenetic facies. Pet Explor Dev 35(5):526-540

Publisher's Note Springer Nature remains neutral with regard to jurisdictional claims in published maps and institutional affiliations. 